\title{
La inconstitucionalidad del trámite establecido en el Código Procesal Civil para resolver la excepción de oscuridad o ambigüedad en el modo de proponer la demanda
}

Juan Morales Godo

\section{Introducción}

La hipótesis de la cual partimos y pretendemos demostrar, es que el demandado puede verse colocado en un verdadero estado de indefensión, cuando interpone la excepción de oscuridad o ambigüedad en el modo de proponer la demanda. ¿Por qué en una situación de indefensión?, por el trámite común para todas las excepciones y defensas previas establecido en el Código Procesal Civil, sin que se haga ningún tipo de diferencia respecto de la excepción en comentario. En efecto, el demandado tiene la carga de contestar la demanda antes de que el Juez resuelva la excepción ya mencionada, la misma que recién se definirá en la audiencia de saneamiento. El tema se complica en la vía procedimental del proceso sumarísimo, en la que el momento para interponer las excepciones coincide con el momento para contestar la demanda.

Pero, ¿cómo contestar la demanda si el demandado está indicando que es oscura o ambigua, que no existe claridad en la pretensión planteada, en los hechos descritos, en la designación de las partes, etc.?. Si bien, el contestar la demanda no es una obligación, sino una carga procesal, el no contestar le puede ocasionar ciertos perjuicios, siendo el de mayor repercusión la posibilidad de que el juez juzgue anticipadamente el proceso, haciendo uso de la presunción relativa de verdad, ante la situación de rebeldía que se genera automáticamente por no contestar la demanda.

El demandado, en consecuencia, debe contestar la demanda, aún cuando la misma es oscura o ambigua. ¿Esta situación es admisible? Recordemos que una de las garantías que constituye parte del contenido del debido proceso es el derecho de defensa, que se inicia - en lo que se refiere al deman- 
dado- por la toma de conocimiento del contenido de la demanda, esto es, el correcto emplazamiento. ¿Se violenta el debido proceso si el demandado "debe» contestar la demanda aún cuando ésta no sea clara?. La respuesta resulta afirmativa, porque es obligar al demandado a formular su defensa sin tener un exacto conocimiento de los alcances de la demanda.

¿Qué está ocurriendo en la experiencia judicial?. La situación no se resuelve con meridiana claridad, imponiéndose el trámite previsto en el Código Procesal Civil, sin que, a nuestro parecer, se haya adoptado algún criterio uniforme jurisprudencial que elimine la posibilidad de colocar en una situación de indefensión al demandado. En efecto, el demandado que ha interpuesto la excepción en referencia, se ve precisado a contestar la demanda señalando los puntos que no aparecen claros; en buena cuenta, ejerce una defensa mediatizada por la imprecisión de la propia demanda, y no tiene mas posibilidad de precisar su contestación, ya que de ampararse la excepción, se le obliga al demandante a esclarecer su demanda, sin que el demandado tenga un correlativo derecho a ampliar el contenido de su contestación de la demanda.

Analicemos el tema con mayor precisión, y para ello es imprescindible partir de una concepción de la institución procesal de las excepciones.

\section{Concepto moderno de la excepción}

Para definir la institución de la excepción, debemos precisar los conceptos de acción, pretensión, contradicción y oposición, ya que los diversos contenidos que se le ha brindado a los mismos, han provocado una gran confusión, de la que no es ajena la propia institución en estudio.

Esta confusión proviene de la tradición civilista en el tratamiento de temas procesales, bajo la consideración de que el proceso es solo asunto de procedimiento; y así, como no existía una clara distinción entre la acción y la pretensión, de la que no es ajeno nuestro Código Civil de 1984, tampoco se lograba diferenciar la contradicción de la excepción, considerando a esta última en el razonamiento de Coviello como «la posibilidad de hacer valer un derecho propio para hacer ineficaz en todo o en parte la acción del adversario, que, vista en sí misma, sería fundada». ${ }^{1}$ Notamos

1 Nicolás Coviello, Doctrina General del Derecho Civil, Unión Tipográfica Editorial Hispano-Americana, México, 1949, p. 567. 
aquí que se considera a la excepción como el medio para atacar la acción, y no solo ello, sino también para atacar la pretensión usando cualquier medio de defensa, confundiéndola con la oposición o medio de defensa o, en todo caso, no precisando la diferencia conceptual con la misma.

Partimos, asumiendo que la acción es el derecho público, subjetivo, abstracto y autónomo, por el cual todo sujeto de derecho está en la aptitud de acudir al órgano jurisdiccional en busca de tutela jurídica, a fin de que se solucione un conflicto de intereses o se elimine una incertidumbre con relevancia jurídica. Por otro lado, la contradicción sería el equivalente al derecho de acción, pero desde la perspectiva del demandado, existiendo entre ambas una diferencia en cuanto al tiempo; en efecto, mientras el actor puede hacer uso de su derecho de acción en cualquier momento, el demandado solo podrá hacer uso del derecho de contradicción dentro de los plazos fijados para cada una de las vías procedimentales diseñadas por el sistema procesal. Otra diferencia es que una precede necesariamente a la otra; para que el demandado haga uso del derecho de contradicción, implica que antes el demandante ha hecho uso de su derecho de acción; sin previo uso del derecho de acción, el derecho de contradicción no tiene posibilidad de manifestación. En consecuencia, la contradicción es el derecho que tiene el demandado de acudir al órgano jurisdiccional en busca de tutela. Y así como no debe confundirse la acción con la pretensión, tampoco debe confundirse la contradicción con la oposición o medio de defensa. Son dos vías paralelas que permiten el acceso a la jurisdicción por parte del demandante (acción) y del demandado (contradicción). El Estado le brinda a ambas partes la posibilidad de acceder en términos igualitarios al servicio de justicia, independientemente de la relación sustancial que se pretende en la demanda y sobre la cual el demandado reclama su libertad. ${ }^{2}$

A su vez, la pretensión es la manifestación de voluntad por la cual, un sujeto de derecho exige algo a otro sujeto. Mientras, la oposición vendría a ser la contrapartida de la pretensión, desde la posición del emplazado, por ello algunos la denominan contrapretensión, ${ }^{3}$ porque en realidad lo

2 Ugo Rocco, Tratado de Derecho Procesal Civil, Vol. I; Ed. Temis-Depalma, BogotáBuenos Aires, 1969, p. 321.

3 Hernando Devis Echandía, Teoría General del Proceso, T. I., Ed. Universidad, Buenos Aires - Argentina, 1984, p. 251. En realidad, el destacado procesalista colombiano estaba citando a Guasp, al señalar: "Oposición y pretensión son actos de voluntad de igual 
que ocurre es que se opone a la pretensión del actor. Es la defensa de fondo o de forma que realiza el demandado. Mientras la oposición es lo genérico pues comprende la defensa de fondo y de forma, la excepción es lo específico, pues comprende solo la defensa de forma. El demandado, en su defensa puede optar por varias alternativas. Algunas de ellas, pueden estar relacionadas al fondo de la causa, como por ejemplo, cuando en una pretensión de dar suma de dinero, puede señalar que no debe la suma reclamada ya que nunca se obligó a ello, o que ya pagó una parte, y lo que estaría adeudando sería una suma menor que la reclamada, o que en efecto reconoce adeudar, pero solicita se le conceda un plazo para cumplir con la obligación reconocida. En todas estas situaciones mencionadas, hay una referencia al fondo de la causa. Pero, también podría ocurrir que el demandado se defienda señalando que el actor no ha sido la persona que le prestó el dinero, sino su hermano; en esta situación hay un cuestionamiento a la pretensión pero en su aspecto formal; no niega la deuda; lo que niega es que el actor sea la persona con quien entabló la relación jurídica sustancial. Este tipo de defensa, dirigida a cuestionar la pretensión en sus aspectos formales se hacen valer a través de las excepciones.

De lo expuesto anteriormente, deducimos que la excepción no es un instituto que se oponga a la acción del actor. La acción una vez ejercitada, es decir, una vez que se acude al órgano jurisdiccional, desaparece y queda el proceso con los correspondientes actos procesales. La excepción no ataca la acción; ataca la pretensión, pero no al mérito de la misma, sino que se plantean algunos aspectos distintos a la demanda, que persiguen evitar que se emita un pronunciamiento sobre el fondo, cuestionándose el defecto o la omisión de algún presupuesto procesal o de alguna de las condiciones de la acción. Existe una correspondencia, un paralelismo entre la acción y la contradicción, de la misma forma como la hay entre la pretensión y la oposición o medio de defensa, una de cuyas modalidades es a través de las excepciones.

naturaleza y contrapuestos que solo se diferencian en el efecto negativo o positivo que persiguen: ésta se propone vincular al demandado o sindicado, en determinado sentido y para ciertos efectos jurídicos concretos, mediante la sentencia (efecto positivo); aquella trata de evitar esa sujeción (efecto negativo) mediante el rechazo de la pretensión en la sentencia o impedir que se pronuncie sentencia e inclusive que se dé curso al proceso. Se trata, como observa Guasp, del "anverso y reverso de una misma figura" y de una auténtica contrapretensión". 
Couture, ${ }^{4}$ se inclinó por considerar la excepción, como la acción del demandado, equivalente a defensa. El demandante ataca con la acción, mientras el demandado se defiende con la excepción, decía el célebre procesalista uruguayo. Esta concepción obedece al concepto que proviene del derecho romano, donde no existía una expresión equivalente a la pretensión, ya que la acción era el derecho mismo, de tal forma que acción y pretensión eran la actio romana. ${ }^{5}$

Alsina, por su parte, tampoco resulta esclarecedor, considerando que existen dos acepciones respecto de la excepción. En efecto, refiere que según la primera concepción, la excepción sería todo medio de defensa que el demandado opone al demandante, reproduciendo lo que existió en algún período del derecho romano. Una segunda acepción considera que la excepción es la udefensa dirigida a paralizar el ejercicio de la acción o a destruir su eficacia jurídica, fundada en una omisión procesal o en una norma substancialn. ${ }^{6}$ Como podemos observar, el procesalista argentino no llega a precisar el concepto de excepción, a pesar de que la segunda acepción se aproxima a la definición que hemos vertido líneas arriba, sobre todo, si consideramos que por «omisión procesal y norma substancial" lo podemos entender como la omisión o defecto de algún presupuesto procesal o condición de la acción.

Tampoco se puede considerar que la excepción es el medio, a través del cual el demandado plantea todos sus medios de defensa. ${ }^{7}$ La Excepción es una institución netamente procesal, y si bien puede producir efectos en las relaciones sustanciales, son defensas tendentes a esclarecer la validez de la relación jurídico procesal, con independencia de la repercusión, en algunos casos, sobre la relación jurídico sustancial.

Para que se declare la validez de la relación jurídico procesal, es preciso que se configuren los presupuestos procesales y las llamadas condiciones de la acción. En sentido estricto, sin embargo, sería suficiente que se cumpla los primeros, ya que las condiciones de la acción son requisitos

4 Eduardo Couture, Fundamentos de Derecho Procesal Civil, Ed. Depalma, Buenos Aires- Argentina, 1978, p. 117

5 Bernardo Windscheid, «Las pretensiones jurídicas. Las excepciones». Ensayo, compilado por César Castañeda, Excepciones Procesales, Palestra, Lima, pp. 18-19.

6 Hugo Alsina, Tratado Teórico Práctico de Derecho Procesal Civil y Comercial, T. III, p. 79.

7 Hernando Devis Echandía, Teoría General del Proceso, T. I., Universidad, Buenos Aires-Argentina, 1984, p. 261. 
para un pronunciamiento sobre el fondo de la causa y no para que se declare la validez de la relación jurídico procesal. Por ello, en algunas legislaciones las condiciones de la acción las examina el juez al momento de dictar sentencia y no en la etapa de postulación. Sin embargo, la opción de nuestro legislador ha sido posibilitar el examen de estos requisitos en el momento del saneamiento, cuando la deficiencia u omisión sean evidentes, manifiestas. En estos casos, como se trata de un pronunciamiento anticipado, coincide con el examen de los presupuestos procesales y por ello se les considera como un requisito para que se declare la validez de la relación jurídico procesal.

En consecuencia, concordamos con Monroy, que define la excepción como el instituto procesal a través del cual el demandado, y eventualmente el demandante en caso de reconvención, ejercen su derecho de defensa, denunciando la existencia de una relación jurídico procesal inválida por omisión o defecto de algún presupuesto procesal o de alguna condición de la acción. ${ }^{8}$ Rocco, tiene una posición parecida cuando señala que los hechos impeditivos, modificativos y extintivos de las relaciones jurídico procesales, cuando sean denunciados en juicio, dan lugar a las llamadas excepciones de derecho procesal. Es menester, sin embargo, aclarar que, el célebre procesalista italiano, señala que las excepciones constituyen un instituto netamente procesal, por lo que la clasificación de excepciones sustanciales y excepciones procesales, no es correcta. Pero, acierta cuando las excepciones las refiere para denunciar los hechos impeditivos, modificativos y extintivos de la relación jurídico procesal.

El tema resulta clarificador cuando nos referimos a los presupuestos procesales, pero no lo es tanto cuando nos referimos a las condiciones de la acción, ya que éstos están referidos al fondo de la causa. Son requisitos para que el juez se pronuncie sobre el fondo, pero el examen de ellos implica un examen de la pretensión misma. ¿Significa ello que por estar referidas a la pretensión del actor o eventualmente del demandado, es decir, al fondo de la causa, se confundiría con los medios de defensa?; en todo caso, ¿cuál sería la diferencia?. Las llamadas condiciones de la acción, efectivamente, implican un examen del fondo de la causa, pero no para negar o afirmar el contenido de la pretensión, que se haría valer a través de los medios de defensa. Tanto el interés para obrar, como la legitimación para obrar, y la voluntad de la ley, consideradas como las condiciones de la

8 Juan Monroy Gálvez, Temas de Proceso Civil, Studium, Lima, pp. 102-103. 
acción, si bien su examen forma parte de la pretensión planteada, no cuestionan el mérito mismo de la pretensión, sino los aspectos relacionados con la constitución de la relación jurídico procesal.

El ejemplo utilizado líneas arriba, referido a una deuda por determinada suma de dinero, podría ayudarnos a clarificar el tema. Cuando el demandado se defienda señalando que no adeuda suma alguna, por no haberla recibido en ningún momento, que es totalmente falsa la supuesta obligación reclamada, o que adeuda una suma de dinero menor por haber cancelado una parte en anterior oportunidad, etc., estamos frente a medios de defensa que utiliza el demandado frente a la pretensión del actor. Estos medios de defensa se dirigen al fondo mismo de la pretensión, es un cuestionamiento al mérito de la causa.

Pero, el demandado puede cuestionar la omisión o defecto de alguna de las condiciones de la acción, como por ejemplo, cuando señala que el titular de la obligación, esto es, el acreedor, no es el demandante, sino otra persona; no niega la obligación, no niega el mérito de la causa, solo refiere que en la pretensión reclamada existe un problema de titularidad. Se agrava la situación si alega que él no es el titular de la relación jurídica sustantiva, indicando que no es el deudor. Parecería, en este caso, que se trata de un tema de fondo, pero, en realidad si bien está referida a la pretensión del actor, el tema es la titularidad pasiva. Puede que la deuda exista, solo que él no es el deudor, por no haber integrado la relación jurídica sustancial. No niega ni afirma la obligación contenida en la pretensión del actor, solo que no es el titular pasivo de la misma. Distinto es que se defienda el demandado negando totalmente la deuda, sin cuestionar la titularidad. En este último caso, estaríamos frente a un medio de defensa y no a un cuestionamiento de la pretensión respecto de la titularidad; ésta se discutiría a través de la excepción de falta de legitimidad para obrar.

De otro lado, puede el demandado defenderse señalando que el demandante no ha agotado todos los medios necesarios para hacer efectiva su pretensión material, por lo que no se hace indispensable que acuda al poder jurisdiccional en busca de tutela exigiendo un pronunciamiento sobre el fondo de su pretensión, esto es, denunciando una falta de interés para obrar. En este caso, tampoco niega o afirma la pretensión del actor, solo que no existe interés para obrar, que también implica una referencia a la pretensión, pero de orden formal, ya que es el cumplimiento de determinados requisitos para que el juzgador se pronuncie sobre el fondo de 
la causa. Y, finalmente, también puede defenderse el demandado, señalando que no existe voluntad de la ley, esto es, que el caso no es justiciable, por lo que no existe la necesidad de un pronunciamiento sobre el fondo de la causa por parte del órgano jurisdiccional.

Esto último podría considerarse como un tema de fondo, pero en realidad, también es un aspecto de orden formal referido a la pretensión, ya que el sistema jurídico considera el hecho como no justiciable; aquí no hay referencia a si se debe o no la obligación reclamada, solo se afirma que la pretensión no es justiciable.

Sin embargo, es preciso aclarar que tanto en el caso de la falta de interés para obrar, como para los casos no justiciables, nuestro sistema jurídico, en el ámbito civil, no ha previsto la defensa de parte del demandado a través de alguna excepción. Pero, ante la ausencia de un medio específico para ello, y ante la omisión por parte del juez que de oficio - in liminepodría declarar la improcedencia de la demanda, puede, el demandado, plantear se declare la improcedencia de la demanda, por falta de interés para obrar o porque el caso no es justiciable, dentro de los medios de defensa en general al contestar la demanda. Más, es preciso señalar que en el campo penal, cuando estamos frente a un caso, cuyos hechos no configuran ningún tipo penal, esto es, se trata de un caso no justiciable penalmente, existe la excepción de naturaleza de acción.

Ocurre también que buena parte de las excepciones típicas reguladas por nuestro Código Procesal Civil, la razón ulterior es la falta de interés para obrar, como por ejemplo, cuando estamos frente a un caso de caducidad, cosa juzgada, litispendencia, desistimiento de la pretensión, falta de agotamiento de la vía administrativa, conclusión del proceso por conciliación o transacción, y la prescripción extintivo que, como sabemos, tiene la característica especial que solo puede ser planteada por el demandado o por el demandante cuando adopta la posición de demandado frente a una posible reconvención. En todas estas excepciones, la causal de fondo es que existe una falta de interés para obrar, por las razones que de cada una de ellas deriva.

\section{Excepción de oscuridad o ambigüedad en el modo de proponer la demanda}

Uno de los presupuestos procesales, además de la competencia del juez y la capacidad procesal, son los requisitos de la demanda. Ante la 
ausencia, o defecto en la exposición de algún requisito de la demanda, sea procesal o sustancial, procede la excepción de oscuridad o ambigüedad en el modo de proponer la demanda, siempre que ello conlleve que no se entienda claramente qué es lo que pretende el actor, cuáles los hechos en que se apoya, quiénes son los sujetos que deben intervenir como partes, etc.

Tiene, como lo hace notar Alvarez, una raigambre constitucional, ${ }^{9}$ ya que está destinada a proteger el derecho de defensa. En efecto, el demandado debe tomar conocimiento con la mayor precisión posible quién lo demanda, qué es lo que demanda y porqué lo demandan, a fin de no encontrarse en desventaja frente al actor, ya que al notificársele el traslado de la demanda, pesa sobre él la carga de contestar la demanda, y para ello debe conocer con la mayor precisión la pretensión, los hechos, los medios probatorios, los anexos, y la identificación de quien lo está demandando. La demanda, por ello, debe ser clara y exacta, coherente, sin ambigüedades; de no ser así, el demandado no podría ejercer su derecho de defensa en forma plena. También es importante para el juzgador, ya que le permitirá dilucidar el conflicto sin dificultad, sin infringir el principio de congruencia.

Esta excepción es conocida también con el nombre de oscuro libelo o defecto legal en el modo de proponer la demanda, y al decir de Alsina «no se refiere al fondo o justicia de la pretensión, sino que solo es procedente cuando por su forma la demanda no se ajuste a los requisitos y solemnidades que la ley prescribe [...]». ${ }^{10}$ En consecuencia, deberá cumplirse con los requisitos de forma señalados en los arts. $424^{\circ}, 425^{\circ}$ y $130^{\circ}$ del CPC y que son válidos para todas las demandas y, además, los requisitos procesales y sustanciales específicos existentes para cada demanda, según su naturaleza.

El legendario Caravantes, decía que «la demanda o libelo no es otra cosa que el ejercicio de una acción y siendo este el medio legítimo para reclamar en juicio los derechos que nos competen", agregando que «se llama demanda porque contiene una petición, y libelo, diminutivo de libro, porque las fórmulas que la expresan se exponen en un breve escriton." ${ }^{11}$

9 Luis Álvarez, Germán Neuss y Horacio Wagner, op.cit., p.196.

10 Hugo Alsina, op.cit., T. III, p. 110.

11 Citado por Isidoro Eisner, «La Excepción de defecto legal (oscuro libelo) frente a la exigencia de contestar la demanda", en: Excepciones Procesales, Compilado por César Castañeda, Palestra, Lima, p. 235. 
Son muchos los supuestos válidos que justifican la interposición de la excepción en comentario, y dependerá de una acuciosa labor jurisprudencial su delimitación, teniendo en consideración la importancia de la omisión, a fin de no caer en un excesivo formalismo que impida el cumplimiento de la finalidad del proceso. La omisión u oscuridad en el modo de proponer la demanda debe ser de tal importancia que pueda colocar al demandado en una situación real de dificultad para contestar correctamente la demanda, es decir, no debe perturbar el derecho de defensa del demandado. El juez debería rechazar la excepción, cuando ésta es manifiestamente maliciosa, o peca de excesivo formalismo, exigiéndose el cumplimiento estricto riguroso de las formalidades establecidas en los artículos $130^{\circ}, 424^{\circ}$ y $425^{\circ}$ del CPC, cuando en realidad, no todas las formalidades van a colocar al demandado en una situación de indefensión. Por ello, su interpretación siempre debe ser restrictiva y en la duda debe estarse por su improcedencia. ${ }^{12}$ Ejemplo de ello, tenemos en los casos que el actor ha errado en la invocación de las normas legales, sin embargo, ha hecho una correcta descripción de la institución jurídica que se pretende; cuando se ha omitido adjuntar copias de la demanda para ser entregadas al demandado en el momento del emplazamiento cosa que puede subsanarse sin necesidad de interponer la excepción analizada.

Colombo, explica que «la demanda debe ser exacta y clara porque de otro modo la defensa del demandado no podría ser plena y porque es el primer punto obligado de referencia que ha de tener la sentencia», agregando que «la procedencia de la excepción de defecto legal requiere de un equilibrio entre dos extremos: el demandado no debe ser colocado en estado de indefensión; no debe exigirse al demandante la exposición de datos que no le es posible obtener». ${ }^{13}$ Este equilibrio que debe procurar el juez, es indispensable para que la excepción cumpla realmente la finalidad para la cual se ha instituido, y no se convierta en un recurso malicioso, cuyo único propósito es dilatar el proceso.

Caravantes, nos precisa con extraordinaria claridad que la excepción de defecto legal en el modo de proponer la demanda, "no se refiere al fondo o justicia de la demanda, sino que solo tiene lugar cuando la forma de la

12 Luis Álvarez, Germán Neuss y Horacio Wagner, Manual de Derecho Procesal, Astrea, Buenos Aires, 1992, p. 196.

13 Carlos J. Colombo, Código de Procedimiento Civil y Comercial, Abeledo Perrot, Buenos Aires, 1964, pp. 300-301. 
demanda, esto es, el modo de formular la pretensión, adolece de vicio o no se ajusta a los requisitos y solemnidades que prescribe la ley para que pueda ser admitida por el juez. Tal sucederá cuando no se fije con precisión lo que se pida [...] o no conste la persona contra quien se proponga $o$ la que la entable o no se expongan sucintamente y numerados los hechos $y$ los fundamentos de derecho $\left[\ldots . .{ }_{x} .{ }^{14}\right.$

Alsina, nos pone innumerables ejemplos de la jurisprudencia argentina, que nos pueden servir de referencia para la interpretación de las normas relativas a los requisitos de la demanda. Así, se ampara la excepción cuando no se fija con precisión lo que se pide, ejemplo: cuando no se estiman los daños y perjuicios en la demanda de indemnización. También procede cuando la exposición de los hechos no es suficientemente clara, o se omiten circunstancias que se consideran indispensables; cuando se presentan documentos redactados en idioma extranjero, sin traducción; en la demanda de locación de servicios cuando no se precisa en qué época y dónde se prestaron; en la demanda por cobro de mercadería si no se especifica la clase y la época de su entrega; si no se indica el lugar y la hora en que acaeció el accidente de tránsito que motiva la demanda de daños y perjuicios, etc. ${ }^{15}$ En realidad, la claridad exigida está referida básicamente a la pretensión, de tal forma que el petitorio y la causa petendi estén descritas de tal forma que permitan su comprensión sin ambigüedades. Recordemos que el petitorio, resulta ser la calificación jurídica resumida de la pretensión, mientras que la causa petendi está conformada por los fundamentos de hecho y de derecho. Sin embargo, no son las únicas exigencias, como es fácil observar de la lectura de los artículos $424^{\circ} \mathrm{y}$ $425^{\circ} \mathrm{del}$ CPC.

La Cuarta Sala Civil de la Corte Superior de Lima, en el expediente No 162-96, con fecha 08 de abril de 1996, respecto de la excepción de oscuridad o ambigüedad en el modo de proponer la demanda, señalaba lo siguiente: "[...]. Que las excepciones denuncian la invalidez de una relación procesal, y por tanto es derecho del justiciable proponerla en todo proceso en que puedan existir vicios que lo afectan; [...] que, en este sentido la actora (sic) ha propuesto la excepción de oscuridad y ambigüedad

14 Cirado por Isidoro Eisner, «La Excepción de defecto legal (oscuro libelo) frente a la exigencia de contestar la demanda», en: Excepciones Procesales, César Castañeda (comp.), Palestra, Lima, p. 238.

15 Hugo Alsina, op. cit., T. III, pp. 111-114. 
en el modo de proponer la demanda, fundamentándola en que el petitorio de la demanda no es claro y preciso y por lo tanto no existe una conexión lógica entre los hechos expuestos y la pretensión solicitada; [...] que, ciertamente se debe tener en cuenta que la demanda no es clara en su pretensión, toda vez que la parte actora si bien es verdad pretende el resarcimiento del pago de una indemnización por daños y perjuicios y por lucro cesantes por los demandados, no precisa saber de qué contratos se derivan los mencionados daños y perjuicios que invoca; [...] que, además, la demanda es ambigua, por cuanto solo se demanda al Ministerio de Economía y Finanzas y al Banco de la Nación, sin embargo no acciona contra Raúl Armando Céspedes Villanueva -Ex Director General de la empresa accionante- que según se desprende del tenor de la demanda es el principal responsable de los daños y perjuicios causados en contra de la referida accionante, $y$ habiéndose instaurado sobre estos hechos proceso penal al mencionado Céspedes Villanueva, por lo tanto, no existe una conexión lógica entre los hechos de la demanda y el petitorio; $[. .]. »{ }^{16}$ Como apreciamos hay una incidencia en la pretensión del actor, que no aparece claramente descrita, pero además en los que deberían ser considerados como parte en el proceso.

Como es obvio es una excepción de puro derecho, por lo que no será necesaria la actuación de medios probatorios. De la lectura de la demanda se desprenderá si es clara u oscura, si se presta para diversas interpretaciones en lo que pretende el actor.

Asimismo, debe considerarse que el demandante al absolver el trámite de la excepción, puede subsanar el defecto formal, situación ésta que favorecería la posición del demandado que podrá contestar la demanda con pleno y claro conocimiento del contenido de la misma. De no ser así, el juez deberá resolver la excepción en la etapa correspondiente al saneamiento.

16 Alberto Hinostroza, Jurisprudencia Civil, T. II, FECAT, Lima, 1997, pp. 480481. 


\section{IV. ¿̇ncongruencia entre la excepción de oscuridad o ambigüedad en el modo de proponer la demanda y la carga de contestar la demanda?}

Hemos señalado que cuando las demandas no están redactadas en forma clara, precisa, sin ambigüedades, cuando no se entiende lo que pretende realmente el demandante, en fin, cuando no se cumple con los requisitos formales y sustanciales en la confección (que coloca al demandado en una situación complicada para contestar), procede la interposición de la excepción de oscuridad o ambigüedad en el modo de proponer la demanda (Art. $446^{\circ}$ inc. 4 del CPC).

Si bien constituye un avance notable que el legislador haya considerado la excepción en comentario, parecería una incongruencia con lo regulado por el Art. $447^{\circ}$ del CPC, cuando señala que las excepciones se sustanciarán en cuaderno separado «sin suspender la tramitación del principal». Ello quiere decir, que el demandado deberá contestar la demanda necesariamente, aun cuando ésta sea oscura o ambigua, ya que no va a ser posible que la excepción planteada sea resuelta antes que se venza el plazo para contestarla, y ello ocurre en cualquiera de las vías procedimentales diseñadas por el Código Procesal Civil.

En efecto, el plazo para contestar la demanda en el proceso de conocimiento es de treinta días, siendo diez para interponer excepciones; en los procesos abreviados el plazo para contestar la demanda es de diez días y cinco para plantear excepciones; y, en los procesos sumarísimos, el plazo para contestar la demanda es de cinco días y tres para interponer excepciones, debiendo plantearse simultáneamente las excepciones. Pero, resulta que las excepciones en todas las vías procedimentales se resuelven en la etapa de saneamiento, la misma que es posterior, necesariamente, a la contestación de la demanda. Nuestra inquietud está centrada básicamente en la excepción de oscuridad o ambigüedad en el modo de proponer la demanda. En lo que se refiere a la suspensión del trámite del cuaderno principal, ya que es positiva la legislación en lo referente a las demás excepciones, como una forma de fomentar la celeridad procesal, máxime con la experiencia histórica que tuvieron las excepciones, las que fueron utilizadas con picardía, con el propósito de dilatar el proceso.

Sin embargo, como señala Eisner, «lo que falta a la lógica y a la razón es que en el caso de demanda defectuosa por «oscuro libelo", en la que no se ha expuesto con claridad ni precisión lo que se alega o pretende, causa y 
objeto de la petición, o en la que ni siquiera se alcanza a comprender lo que se pide de la jurisdicción y del adversario, este sea forzado por la ley a contestar la demanda y asumir a ciegas su defensa. [...] En este último supuesto, la carga impuesta al demandado de que responda a un libelo oscuro, pese a su seguridad, lesiona no solo el buen sentido sino el concepto mismo de la excepción de defecto legal que el código recepta para repeler a toda demanda defectuosam. ${ }^{17}$

Creemos que, solo para el caso de la excepción en comentario, debió establecerse la necesidad de que se resuelva previamente, antes de que el demandado asuma la carga de contestar la demanda. Tal como está legislado en nuestro Código Procesal Civil, podríamos considerar que para dicha excepción, se trataría de una norma inconstitucional, porque atenta contra el debido proceso, y en concreto transgrede el legítimo derecho de defensa del demandado. En todo caso, si la excepción es amparada y el demandante aclara su demanda, en los términos señalados en la resolución del juez, deberá correrse nuevo traslado para que el demandado conteste la demanda corregida, ampliando de esta forma su contestación ya efectuada.

Algunas resoluciones de los estrados judiciales peruanos traducen una concepción cabal de la excepción comentada, aún cuando no se haga ninguna referencia a una posible inconstitucionalidad de la norma que establece la carga de contestar la demanda al demandado. Así, en el expediente No 327-97, en los seguidos por Banco Internacional del Perú contra J. F. Ingenieros Asociados y otros, sobre obligación de dar suma de dinero, la Sala Civil No 1 de la Corte Superior de Lima, con fecha 07 de julio de 1997, señalaba lo siguiente: «[...] La excepción de oscuridad o ambigüedad se produce cuando el tenor de la demanda no se halla precisada con claridad la pretensión o pretensiones del demandante, y en tal sentido impide el cabal ejercicio del derecho de contradicción de los emplazados. [...]". ${ }^{18}$ Efectivamente, en la mayoría de los casos, la oscuridad o ambigüedad estará referida a la pretensión (¿qué se pide? ¿por qué se pide?); sin embargo, la oscuridad o ambigüedad también podría estar referida a quién se pide. Pero, lo importante, es que queda claro que se trata de una de-

17 Isidoro Eisner, «La Excepción de defecto legal (oscuro libelo) frente a la exigencia de contestar la demanda", op. cit., p. 241.

18 Marianella Ledesma, Jurisprudencia actual, T. I, Gaceta Jurídica, Lima, 1997, p. 416. 
manda oscura, que perjudica el derecho de defensa del demandado, toda vez que lo coloca en una situación de defensa a ciegas o de una real indefensión. Cuando la resolución se refiere al derecho de contradicción, debemos entender que se refiere a la oposición o medio de defensa. ${ }^{19}$

La misma Sala No 1 de la Corte Superior de Lima, en el expediente No 442-7-97, en los seguidos por Carmen Poveda de Pacheco con Graciela Arriaga Tenazoa, sobre interdicto de recobrar, con fecha 14 de julio de 1997, explicaba con mayor claridad el tema, señalando lo siguiente: «[...] A que la excepción de oscuridad o ambigüedad en el modo de proponer la demanda procede frente a incumplimientos de las formas de la demanda o su planteo confuso de manera tal, que impide el efectivo ejercicio del derecho de defensa al no poder el demandado negar o reconocer cada uno de los hechos expuestos en la demanda [... $"{ }^{20}$

\section{Naturaleza jurídica de la excepción de oscuridad o ambigüedad en el modo de proponer la demanda}

La excepción en comentario es de carácter dilatoria, toda vez que el juez no dará por concluido el proceso, sino concederá un plazo para que el demandante esclarezca su demanda. Se trata que el demandante sea más preciso en aquellos aspectos que el demandado ha objetado y que el juez las ha considerado procedentes. Se entiende que esta excepción tiene como propósito que el demandado tenga pleno entendimiento del contenido de la demanda, para que conteste a cabalidad, con plena conciencia del propósito del actor; y su derecho de defensa no se perjudique. Pero, de otro lado, al juez también le interesa que la demanda tenga claridad, para que su pronunciamiento también sea preciso y no pronuncie resoluciones

19 Por contradicción debemos entender el derecho del demandado de acudir al órgano jurisdiccional en busca de tutela. Al igual que el derecho de acción, es público, autónomo y abstracto; y así como no debe confundirse el derecho de acción con la pretensión que se plantea a través de la demanda, que es la forma como se concreta el derecho de acción, no debe confundirse el derecho de contradicción con la oposición o medio de defensa. Una demanda oscura no impide al demandado acudir al órgano jurisdiccional en busca de tutela, lo que ocurre es que va a perjudicar el derecho de defensa, toda vez que no sabrá con claridad los alcances de la pretensión del actor.

20 Marianella Ledesma, Jurisprudencia actual, op. cit., p. 419. 
equivocadas por partir de un erróneo entendimiento de una demanda ambigua o imprecisa.

Hemos advertido, en el ítem anterior, el problema que se suscita con esta excepción, que puede colocar al demandado en una situación de desventaja, atentatoria a su derecho de defensa. También al debido proceso, toda vez que se ve precisado a contestar la demanda, dentro de los plazos fijados por las distintas vías procedimentales, sin que antes se haya resuelto la referida excepción y, por lo tanto, sin que haya logrado que se esclarezca o que se elimine la ambigüedad denunciada. ¿Cómo contestar una demanda, que el demandado la está denunciando de oscura o ambigua, esto es, que no está claro el propósito del actor?. Ya hemos expresado nuestro punto de vista al respecto, pero lo importante es que cualquiera fuere la solución, ello no modifica la naturaleza dilatoria de la excepción. 